\title{
The Effect of LM25 and LM50 on Hypoglycemia in Chinese T2DM Patients: Post Hoc Analysis of a Randomized Crossover Trial
}

\author{
Wei Li · Fan Ping $\cdot$ Lingling $\mathrm{Xu} \cdot$ Huabing Zhang $\cdot$ Yaxiu Dong • \\ Kang Yu $\cdot$ Yuxiu Li (D)
}

Received: November 23, 2019 / Published online: January 24, 2020

(c) The Author(s) 2020

\begin{abstract}
Introduction: To investigate the safety of insulin lispro Mix 25 and 50 (LM25 and LM50) in hypoglycemia in patients with type 2 diabetes mellitus (T2DM).

Methods: This was a post hoc analysis of a phase IV, randomized, crossover clinical trial in Chinese patients with T2DM switching from premixed human insulin 70/30 (PHI70/30) to LM25 or LM50. Eighty-one subjects received a two-stage crossover protocol of either LM25 or LM50 twice daily for 16 weeks. Habitual diet was taken, and self-monitoring of blood glucose (SMBG) was performed throughout the study period. High-carbohydrate diet (HCD), high-fat diet (HFD) and habitual diet patterns were
\end{abstract}

Enhanced Digital Features To view enhanced digital features for this article go to https://doi.org/10.6084/ m9.figshare.11522673.

W. Li · F. Ping $\cdot$ L. Xu $\cdot$ H. Zhang

Y. Dong · Y. Li $(\bowtie)$

Department of Endocrinology, Key Laboratory of Endocrinology of National Health Commission, Peking Union Medical College Hospital, Chinese Academy of Medical Sciences and Peking Union Medical College, Beijing, China

e-mail: liyx@pumch.cn

K. Yu

Department of Clinical Nutrition, Peking Union

Medical College Hospital, Chinese Academy of

Medical Sciences and Peking Union Medical

College, Beijing, China taken, and $72 \mathrm{~h}$ continuous glucose monitoring (CGM) was performed at the last 3 days of each treatment stage.

Results: The frequencies of nocturnal hypoglycemia in LM50 were lower than those in LM25 under a Chinese habitual diet pattern. The related factors of hypoglycemia in patients with T2DM treated with a LM25 or LM50 regimen were the weight-based daily mean insulin dose and the type of combined oral hypoglycemic agents. Under both HCD and habitual diet patterns, the optimal cut point values of bedtime glucose predicting nocturnal hypoglycemia in LM50 were lower than those in LM25.

Conclusions: The risk of nocturnal hypoglycemia in the LM50 regimen was lower than that in the LM25 regimen under the HCD pattern, and the safety range of bedtime glucose for the LM50 regimen was wider than that of the LM25 regimen in Chinese T2DM patients. Premixed insulin analogs combined with acarbose were more helpful to reduce the incidence of hypoglycemia.

Trial Registration: http://www.chictr.org.cn \#ChiCTR-TTRCC-12002516.

Keywords: Hypoglycemia; Premixed insulin; Type 2 diabetes mellitus 


\section{Key Summary Points}

This was a post hoc analysis of a phase IV, randomized, crossover clinical trial in Chinese patients with type 2 diabetes mellitus (T2DM) switching from premixed human insulin 70/30 (PHI70/30) to insulin lispro Mix 25 (LM25) or insulin lispro Mix 50 (LM50).

Our study investigated the safety of LM25 and LM50 in hypoglycemia in Chinese T2DM patients.

We found that the risk of nocturnal hypoglycemia in the LM50 regimen was lower than that in the LM25 regimen under a high-carbohydrate dietary pattern, and the safety range of bedtime glucose in the LM50 regimen was wider than that in the LM25 regimen in Chinese T2DM patients.

Premixed insulin analogs combined with acarbose were more helpful to reduce the incidence of hypoglycemia.

\section{INTRODUCTION}

In recent years, the prevalence of T2DM has increased rapidly around the world, especially in East Asia [1]. According to the epidemiologic survey in 2013, the prevalence of diabetes in China has reached $10.9 \%$, making China the country with the most diabetic patients [2]. When islet $\beta$ cell failure occurs in patients with T2DM, insulin therapy becomes an inevitable choice. For patients with failed oral hypoglycemic therapy, the American and European guidelines generally recommend basal insulin as the preferred initial insulin formulation [3], while in the Chinese guideline, it is suggested that premixed insulin (analogs) or basal insulin can be used as an option [4]. In fact, two-thirds of Chinese patients with T2DM currently are treated with premixed insulin [5].
This difference in diabetes management is believed to be related to the difference in the pathophysiologic mechanism of T2DM between East Asians and Caucasians. Studies on Chinese and Japanese patients have shown that the decrease of insulin secretion caused by $\beta$-cell dysfunction plays a more important role in the development of diabetes in East Asians [6, 7]. East Asians are also more likely to eat a HCD, so East Asian patients with T2DM are more characterized by postprandial hyperglycemia [8].

Premixed insulin analogs have the advantages of being faster onset and easier to use than premixed human insulin, and they are gradually replacing the status of premixed insulin. Premixed insulin analogs currently on the market have low- and mid-ratio premixed insulin analogs. For example, LM25 (Humalog ${ }^{\circledR}$ Mix25, which contains 25\% insulin lispro and 75\% insulin lispro protamine) and LM50 (Humalog ${ }^{\circledR}$ Mix 50, which contains 50\% insulin lispro and $50 \%$ insulin lispro protamine) are widely used as the starting insulin. The CLASSIFY study and our previous study have confirmed that although the effects of the two types of insulin on glycosylated hemoglobin $\left(\mathrm{HbA}_{1 \mathrm{c}}\right)$ are similar, LM50 provides better postprandial glycemic control than LM25 $[9,10]$.

While paying attention to the efficacy of the two types of insulin, their safety issues, such as hypoglycemia, cannot be ignored. Previous observational studies found that both spontaneous hypoglycemia and insulin-associated hypoglycemia are associated with increased mortality [11-13]. Since insulin-induced hypoglycemia accounts for the vast majority of hypoglycemia events [14], the Joint Commission and the Institute for Safe Medication Practices have designated it as a "highly alert" drug [15]. Therefore, strengthening the study in the features and related factors of hypoglycemia caused by insulin preparations is helpful to reduce the risk of its application. Regarding the difference in hypoglycemia rates between LM25 and LM50, the CLASSIFY study only made a rough comparison, showing no significant difference [9]. A subgroup analysis of the Chinese population in the CLASSIFY study showed that fewer patients reported nocturnal hypoglycemic episodes in the LM50 than LM25 treatment 
group; however, more nocturnal hypoglycemic episodes were reported in the LM50 than LM25 treatment group, both without significant differences [16]. Our study used the data on the percentage of hypoglycemic time recorded by continuous glucose monitoring (CGM)and found that a smaller proportion of the patients on the LM50 regimen spent a high percentage $(>10 \%)$ of their hypoglycemic time compared with those on the LM25 $(p<0.05)$ [10]. This may be related to the fact that CGM is more likely to detect hypoglycemia that is not noticeable at night. The aim of the present post hoc analysis was to further analyze the safety of the two insulins in hypoglycemia to obtain useful tips for clinical decision-making.

\section{METHODS}

\section{Study Design}

The data of the post hoc analysis were from our study on a phase IV, randomized, crossover, open-label, investigator-initiated clinical trial in
Chinese patients with T2DM switching from premixed human insulin 70/30 (PHI70/30) to LM25 or LM50. This clinical trial was registered at http://www.chictr.org.cn (ChiCTR-TTRCC12002516) [10].

The study consisted of a 2 -week screening period and a 2-week lead-in period followed by two 16-week crossover treatment periods (Fig. 1). All subjects continued to receive PHI70/ 30 treatment during the 2 -week lead-in period and then were randomly divided into two treatment arms based on a random number table: one arm received LM25 twice daily while the other arm received LM50 twice daily during the first 16-week treatment stage, and the two arms then switched regimens during the next 16-week treatment stage.

\section{Study Population}

Male or non-pregnant, non-breastfeeding female Chinese T2DM patients at least 18 years of age who had received a stable dose of PHI70/ 30 twice daily (whether combined with oral hypoglycemic agents or not) for at least 90 days

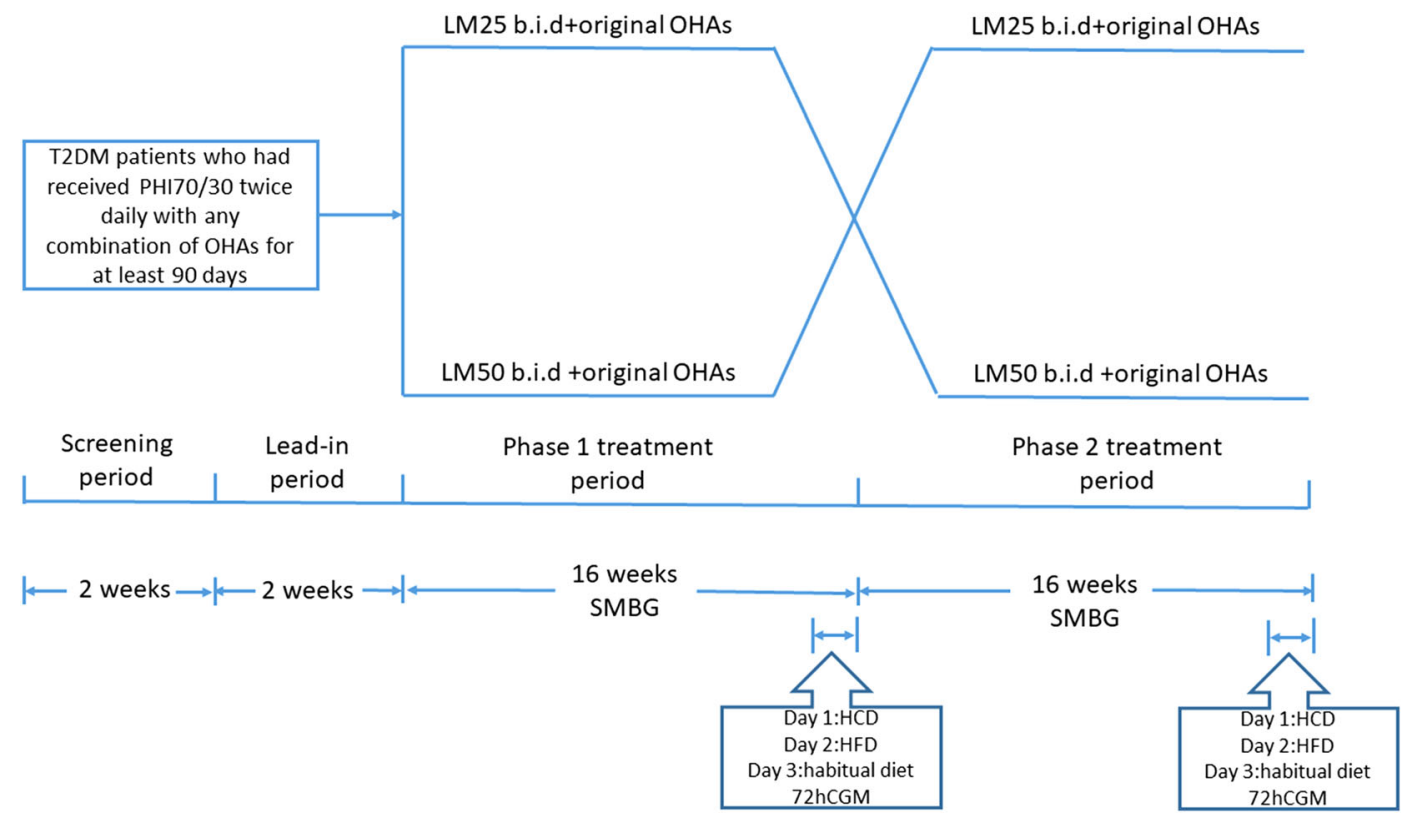

Fig. 1 Subject flow diagram. $C G M$ continuous glucosemonitoring system, $H C D$ high-carbohydrate diet, $H F D$ high-fat diet, LM25 insulin lispro Mix 25, LMSO insulin lispro Mix 50,OHAs oral hypoglycemic agents, $P H I 70 / 30$ premixed human insulin 70/30, $S M B G$ self-monitoring of blood glucose, $T 2 D M$ type 2 diabetes mellitus 
with an $\mathrm{HbA}_{1 \mathrm{c}}$ of $\geq 6.0 \%$ were enrolled to participate in this comparative study on LM25 and LM50. The patients visited the Department of Endocrinology at Peking Union Medical College Hospital (PUMCH) from 1 November 2013 to 31 May 2015.

Key exclusion criteria included the following: patients with liver dysfunction (alanine transaminase or alkaline phosphatase $>2.5$-fold the upper limit of the reference range) or renal insufficiency (serum creatinine $\geq 133 \mu \mathrm{mol} / \mathrm{l}$ for males or $\geq 110 \mu \mathrm{mol} / \mathrm{l}$ for females); patients with other diseases or receiving other drugs that may influence blood glucose (BG) and hemoglobin; patients with an inability to eat normally.

\section{Study Procedures and Treatment}

After recruitment, all subjects were randomly divided into group $\mathrm{A}$ and $\mathrm{B}$ according to a random number table. Group A (LM25/LM50 group) received LM25 twice daily during the first 16-week treatment stage and LM50 twice daily during the next 16-week treatment stage. Group B (LM50/LM25 group) was opposite to group A. The initial total daily dose of LM25 or LM50 was determined according to the total daily dose of the original PHI70/30 and distributed to breakfast and dinner in a 1:1 ratio. When the two arms switched therapy, the initial total daily dose of insulin was the same as the total daily dose of insulin in the previous stage and also distributed to breakfast and dinner in a 1:1 ratio. Insulin dose titration was performed in the first 4 weeks of each 16-week treatment stage. The subjects got a 4-point BG profile by SMBG (preprandial BG of three meals plus bedtime $B G$ at least 1 day every week, adding a BG test while having hypoglycemia symptoms and recording severe hypoglycemia episodes that required others' help). They were followed up every 2 weeks to adjust the insulin dose according to the BG profile (insulin sliding scale was presented in a previous article [10]). The targets of insulin titration were BG $>3.9 \mathrm{mmol} / \mathrm{l}$ and $\leq 6.1 \mathrm{mmol} / \mathrm{l}$ before breakfast and dinner. Insulin doses remained stable for the subsequent 12 weeks of this stage.
The types and dosages of original oral hypoglycemic agents in combination were not adjusted throughout the trial.

During the trial, the subjects were advised to follow the Chinese guidelines for diet control and exercise; $45-60 \%$ of the total daily energy derived from carbohydrates, $25-35 \%$ from dietary fat and $15-25 \%$ from protein. The total daily energy intake was calculated according to the height and weight of each subject. The subjects were required to exercise regularly during the trial. CGM was performed for 3 days at the end of lead-in period and each treatment stage.

During the 3 days of CGM, the subjects received high-carbohydrate test meals (with $56.8-58.4 \%$ of the total energy deriving from carbohydrates, $15.7-17.2 \%$ from protein and $24.4-26.7 \%$ from fat) on day 1 and high-fat test meals (with $39.8-40.7 \%$ of the total energy deriving from carbohydrates, $23.0-24.4 \%$ from protein and $33.0-36.1 \%$ from fat) on day 2 . They continued their habitual diets on day 3 .

\section{Outcome Measures}

At the time of recruitment, the subjects' medical history data (age, gender, duration of diabetes, insulin dose, combined oral hypoglycemic agents, etc.) and anthropometric data [blood pressure, height, weight, body mass index (BMI), waist circumference, etc.] were recorded. In addition, $\mathrm{HbA}_{1 \mathrm{c}}$ and $72 \mathrm{~h}$ CGM were performed at enrollment and at the end of each treatment phase. CGM was conducted using the GOLD CGM system (Medtronic, USA). This system can measure the interstitial glucose (IG) levels every $10 \mathrm{~s}$, record the average value every $5 \mathrm{~min}$ and record 288 measurements daily. The subjects recorded SMBG using an EZ508 meter (Sinomedisite, China) to allow regular insulin dose titration.

Hypoglycemia data came from SMBG and CGM of the subjects. The same hypoglycemia episode recorded by SMBG and CGM was based on the value measured by the SMBG. Hypoglycemia was defined as BG or IG level $\leq 3.9 \mathrm{mmol} / \mathrm{l}$. According to the time of hypoglycemia, it can be divided into total 
hypoglycemia, daytime hypoglycemia (06:00 a.m.-22:00 p.m.) and nocturnal hypoglycemia (00:00 a.m.-06:00 a.m. and 22:00 p.m.-24:00 p.m.). According to the severity of hypoglycemia, it can be divided into mild (BG or $\mathrm{IG} \leq 3.9 \mathrm{mmol} / \mathrm{l}$ and $>3.0 \mathrm{mmol} / \mathrm{l}$ ), moderate (BG or $\mathrm{IG} \leq 3.0 \mathrm{mmol} / \mathrm{l}$ ) and severe hypoglycemia (a severe event characterized by altered mental and/or physical status requiring assistance).

According to the 72-h CGM data, we can get mean blood glucose (MBG), mean amplitude of glucose excursion (MAGE, the mean value of the valid blood glucose excursion amplitudes that were greater than the standard deviation for all the glucose excursions during the given day), the percentage of hypoglycemic time (percentage of time with IG $\leq 3.9$ or $3.0 \mathrm{mmol} / \mathrm{l}$ during a particular day), frequency of hypoglycemia (frequency of hypoglycemic episodes with $\mathrm{IG} \leq 3.9$ or $3.0 \mathrm{mmol} / \mathrm{l}$ excursions during a particular day, allowing up to two consecutive readings above the threshold within the same episode; if a following episode started within $1 \mathrm{~h}$ of the start of the previous episode, they were combined and recorded as one episode) and the proportion of subjects with hypoglycemia. According to the SMBG data, we can get the frequency of hypoglycemia (frequency of hypoglycemic episodes with $\mathrm{BG} \leq 3.9$ or $3.0 \mathrm{mmol} / \mathrm{l}$ during a particular day; if a following episode started within $1 \mathrm{~h}$ of the start of the previous episode, they were combined and recorded as one episode) and the proportion of subjects with hypoglycemia.

\section{Statistical Analysis}

The present study was post hoc in nature. Measurement data were expressed as the mean $\pm \mathrm{SD}$, and count data were expressed as frequency. The rates between the two groups were compared using the chi-square test. The crossover analysis was based on a univariate general linear model, including the treatment regimen and phase and dietary pattern as fixed effects and patients as a random effect. $p<0.05$ was considered statistically significant. For multiple tests, the Bonferroni method was used to correct the test level: $\alpha^{\prime}=\alpha / m \quad(\alpha=0.05$, $m=$ the number of tests). SPSS 22.0 software was used to complete statistical analysis.

\section{Compliance with Ethical Guidelines}

The study was conducted in accordance with the ethical standards of the responsible committee on human experimentation (institutional and national) and with the Helsinki Declaration of 1964, as revised in 2013, and was approved by the PUMCH Ethics Committee. All patients signed informed consent before enrollment.

\section{RESULTS}

\section{Baseline Characteristics of Subjects}

A total of 86 subjects were recruited into the trial, with 81 completing the study. The patient disposition was presented in a previous article [10]. The demographics and baseline characteristics of the subjects are shown in Table 1 . There were 41 subjects ( 14 males and 27 females, age $58.6 \pm 11.2$ years, BMI $25.8 \pm 2.4 \mathrm{~kg} / \mathrm{m}^{2}$ ) in the LM25/LM50 group and 40 subjects (17 males and 25 females, age $61.2 \pm 9.6$ years, BMI $26.6 \pm 2.8 \mathrm{~kg} / \mathrm{m}^{2}$ ) in the LM50/LM25 group. No statistical differences were shown between the two groups in terms of gender composition ratio, age, duration of diabetes, weight, BMI, waist circumference, systolic blood pressure, diastolic blood pressure, total daily insulin dose and oral hypoglycemic agent composition ratio.

\section{Comparison of Hypoglycemia Between LM25 and LM50}

The rate and incidence of hypoglycemia episodes during LM25 and LM50 regimens were compared. The rate of hypoglycemia episodes was the mean number of hypoglycemia episodes per patient per year, and the incidence of hypoglycemia episodes was the percentage of patients with the specified hypoglycemia episode. The data of hypoglycemia came from SMBG of subjects, not including the data of 
Table 1 Demographics and baseline characteristics of subjects

\begin{tabular}{|c|c|c|c|}
\hline & $\begin{array}{l}\text { LM25/ } \\
\text { LM50 } \\
\text { group }\end{array}$ & $\begin{array}{l}\text { LM50/ } \\
\text { LM25 } \\
\text { group }\end{array}$ & $p$ value \\
\hline $\begin{array}{l}\text { Gender (male/ } \\
\text { female) }(n)\end{array}$ & $41(14 / 27)$ & $40(17 / 23)$ & 0.211 \\
\hline Age (years) & $58.6 \pm 11.2$ & $61.2 \pm 9.6$ & 0.446 \\
\hline $\begin{array}{l}\text { Duration of } \\
\text { diabetes (years) }\end{array}$ & $15.2 \pm 9.0$ & $14.2 \pm 8.0$ & 0.124 \\
\hline Weight $(\mathrm{kg})$ & $69.3 \pm 15.2$ & $68.1 \pm 14.5$ & 0.745 \\
\hline BMI $\left(\mathrm{kg} / \mathrm{m}^{2}\right)$ & $25.8 \pm 2.4$ & $26.6 \pm 2.8$ & 0.563 \\
\hline $\begin{array}{l}\text { Waist } \\
\text { circumference } \\
(\mathrm{cm})\end{array}$ & $85.6 \pm 20.6$ & $88.4 \pm 19.1$ & 0.545 \\
\hline $\begin{array}{l}\text { Systolic blood } \\
\text { pressure }(\mathrm{mmHg})\end{array}$ & $120 \pm 12$ & $124 \pm 14$ & 0.540 \\
\hline $\begin{array}{l}\text { Diastolic blood } \\
\text { pressure }(\mathrm{mmHg})\end{array}$ & $71 \pm 10$ & $73 \pm 11$ & 0.626 \\
\hline $\mathrm{HbA}_{1 \mathrm{c}}(\%)$ & $8.0 \pm 1.5$ & $7.6 \pm 1.4$ & 0.247 \\
\hline $\begin{array}{l}\text { Total daily insulin } \\
\text { dose (IU) }\end{array}$ & $42.4 \pm 16.5$ & $38.0 \pm 15.2$ & 0.089 \\
\hline $\begin{array}{l}\text { Type of combined } \\
\text { oral hypoglycemic } \\
\text { agents (\%) }\end{array}$ & & & \\
\hline Metformin & 27 (65.9\%) & $23(57.5 \%)$ & 0.211 \\
\hline Acarbose & $13(31.7 \%)$ & $16(40 \%)$ & 0.239 \\
\hline Thiazolidinediones & $4(9.8 \%)$ & $2(5 \%)$ & 0.179 \\
\hline
\end{tabular}

Data are given as the mean $\pm S D$

$B M I$ body mass index

hypoglycemia during CGM. Corrected significance level $\alpha^{\prime}$ was $0.010 ; p<0.010$ was considered statistically significant. The results showed that the rate of total hypoglycemia and percentage of patients with total hypoglycemia in the LM25 regimen were similar to those in the LM50 regimen $(p>0.010)$. The mean number of nocturnal hypoglycemia episodes per patient per year in the LM50 regimen was lower than that in the LM25 regimen $(1.6 \pm 5.8$ vs.
$3.0 \pm 6.5, p=0.001)$. No severe hypoglycemia episodes were observed in all subjects, regardless of treatment assigned (Table 2).

\section{Effect of Different Dietary Patterns on Blood Glucose Parameters from CGMS During the Treatment of LM25 and LM50}

The variance analysis of the two-stage crossover study showed that there were no significant differences between the stage and subject factors $(p>0.05)$, and there were significant differences in insulin regimen factors and dietary pattern factors $(p<0.05)$. The effects of three different dietary patterns on blood glucose parameters from CGMS were compared. The three different dietary patterns were HCD on day 1, HFD on day 2 and habitual diets on day 3 . The hypoglycemia data came from 72 h CGM of subjects, including mean blood glucose (MBG), mean amplitude of glucose excursion (MAGE), percentage of total hypoglycemia, minimum IG throughout the day and minimum IG in the night. Corrected significance level $\alpha^{\prime}$ was $0.010 ; p<0.010$ was considered statistically significant. The results showed that the percentage of total hypoglycemia in LM50 was lower than that in LM25 in the HCD and habitual diet pattern (HCD pattern: $2.24 \pm 1.12 \%$ vs. $4.28 \pm 1.80 \%, \quad p=0.005$; Habitual diet pattern: $2.16 \pm 1.45 \%$ vs. $3.95 \pm 1.62 \%, p=0.008)$. There were no statistical differences in terms of MBG, MAGE, minimum IG throughout the day and minimum IG in the night between LM25 and LM50 under three dietary patterns (Table 3).

\section{Analysis of Related Risk Factors of Hypoglycemia of Subjects}

Logistic regression analysis was performed using hypoglycemia episodes of subjects $(0=$ No, $1=$ Yes) as dependent variable and possible related factors, such as age $(0=\leq 60$ years old, $1=>60$ years old), duration of diabetes $(0=\leq$ 10 years, $1=>10$ years $)$, BMI $\left(0=\leq 24 \mathrm{~kg} / \mathrm{m}^{2}\right.$, $1=>24$ and $\left.\leq 28 \mathrm{~kg} / \mathrm{m}^{2}, 2=>28 \mathrm{~kg} / \mathrm{m}^{2}\right)$, type of insulin ( $0=\mathrm{LM} 25,1=\mathrm{LM} 50)$, weight-based daily mean insulin dose $(0=\leq 0.50 \mathrm{IU} / \mathrm{kg} /$ day, 
Table 2 Rate and incidence of hypoglycemia during the 32-week study period for subjects with type 2 diabetes treated with LM25 and LM50

\begin{tabular}{|c|c|c|c|c|c|c|}
\hline \multirow[t]{2}{*}{ Episode type } & \multicolumn{2}{|c|}{$\begin{array}{l}\text { Hypoglycemia episodes, per patient per } \\
\text { year (SD) }\end{array}$} & \multirow[t]{2}{*}{$p$ value } & \multicolumn{2}{|c|}{$\begin{array}{l}\text { Subjects with hypoglycemia episode, } \\
n(\%)\end{array}$} & \multirow[t]{2}{*}{$p$ value } \\
\hline & LM25 & LM50 & & LM25 & LM50 & \\
\hline Total & $18.5(10.6)$ & $19.3(10.8)$ & 0.792 & $42(51.9 \%)$ & $40(49.4 \%)$ & 0.896 \\
\hline Daytime & $15.5(9.2)$ & $17.6(9.6)$ & 0.112 & $35(43.2 \%)$ & $36(44.4 \%)$ & 0.962 \\
\hline Nocturnal & $3.0(6.5)$ & $1.6(5.8)$ & 0.001 & $16(19.8 \%)$ & $10(12.3 \%)$ & 0.180 \\
\hline Mild & $13.4(8.9)$ & $13.8(9.0)$ & 0.885 & $26(32.1 \%)$ & $28(34.6 \%)$ & 0.754 \\
\hline Moderate & $5.1(7.2)$ & $5.4(7.3)$ & 0.796 & $16(19.8 \%)$ & $7(8.6 \%)$ & 0.035 \\
\hline Severe & 0 & 0 & ND & 0 & 0 & ND \\
\hline
\end{tabular}

$L M 25$ insulin lispro Mix 25, LM50 insulin lispro Mix 50, ND not determined

Corrected significance level $\alpha^{\prime}$ was $0.010 ; p<0.010$ was considered statistically significant

Table 3 Effect of three different dietary patterns on blood glucose parameters from CGMS

\begin{tabular}{|c|c|c|c|c|c|c|c|c|c|c|c|}
\hline \multirow[t]{2}{*}{$\begin{array}{l}\text { Dietary } \\
\text { pattern }\end{array}$} & \multirow[t]{2}{*}{$\begin{array}{l}\text { Insulin } \\
\text { regimen }\end{array}$} & \multicolumn{2}{|l|}{ MBG } & \multicolumn{2}{|l|}{ MAGE } & \multicolumn{2}{|c|}{$\begin{array}{l}\text { Percentage of total } \\
\text { hypoglycemia }\end{array}$} & \multicolumn{2}{|c|}{$\begin{array}{l}\text { Minimum IG } \\
\text { throughout the } \\
\text { day }\end{array}$} & \multicolumn{2}{|c|}{$\begin{array}{l}\text { Minimum IG in } \\
\text { the night }\end{array}$} \\
\hline & & $\mathrm{mmol} / \mathrm{l}$ & $p$ & $\mathrm{mmol} / \mathbf{l}$ & $p$ & $\overline{\%}$ & $p$ & $\mathrm{mmol} / 1$ & $p$ & $\mathrm{mmol} / \mathrm{l}$ & $p$ \\
\hline \multirow{2}{*}{$\begin{array}{l}\mathrm{HCD} \\
\quad(\mathrm{D} 1)\end{array}$} & LM25 & $9.6 \pm 2.2$ & 0.665 & $5.8 \pm 2.9$ & 0.726 & $4.28 \pm 1.80$ & 0.005 & $2.8 \pm 1.2$ & 0.625 & $2.8 \pm 1.3$ & 0.625 \\
\hline & LM50 & $9.2 \pm 2.5$ & & $5.6 \pm 2.8$ & & $2.24 \pm 1.12$ & & $3.0 \pm 1.2$ & & $3.0 \pm 1.2$ & \\
\hline \multirow{2}{*}{$\begin{array}{l}\text { HFD } \\
\text { (D2) }\end{array}$} & LM25 & $9.4 \pm 2.1$ & 0.862 & $5.5 \pm 2.7$ & 0.838 & $2.81 \pm 1.27$ & 0.085 & $3.0 \pm 1.2$ & 0.820 & $3.0 \pm 1.2$ & 0.795 \\
\hline & LM50 & $9.5 \pm 2.2$ & & $5.6 \pm 2.7$ & & $2.30 \pm 1.05$ & & $3.0 \pm 1.3$ & & $3.1 \pm 1.1$ & \\
\hline \multirow{2}{*}{$\begin{array}{l}\text { Habitual } \\
\text { (D3) }\end{array}$} & LM25 & $9.6 \pm 2.0$ & 0.804 & $5.6 \pm 2.8$ & 0.820 & $3.95 \pm 1.62$ & 0.008 & $3.1 \pm 1.2$ & 0.760 & $3.1 \pm 1.3$ & 0.846 \\
\hline & LM50 & $9.3 \pm 2.6$ & & $5.5 \pm 2.8$ & & $2.16 \pm 1.45$ & & $3.2 \pm 1.2$ & & $3.1 \pm 1.2$ & \\
\hline
\end{tabular}

Data are given as the mean $\pm S D$

$L M 25$ insulin lispro Mix 25, LM50 insulin lispro Mix 50, HCD high-carbohydrate diet, $H F D$ high-fat diet, $M B G$ mean blood glucose, $M A G E$ mean amplitude of glucose excursion, $I G$ interstitial glucose

Corrected significance level $\alpha^{\prime}$ was $0.010 ; p<0.010$ was considered statistically significant

$1=>0.50 \mathrm{IU} / \mathrm{kg} /$ day $)$ and combined oral hypoglycemia agent $(1=$ acarbose, 2 = others $)$ as independent variable. The results showed daily average insulin dose and combined oral hypoglycemia agent were related risk factors for hypoglycemia episodes (OR 2.035 and 1.793, respectively) (Table 4 ). The hypoglycemia data came from the SMBG of subjects, not including the data of hypoglycemia during CGM.

\section{Predictive Value of Bedtime IG on Nocturnal Hypoglycemia}

The $72 \mathrm{~h}$ CGM data of all subjects were analyzed. Bedtime IG was defined as the IG value at 
Table 4 Logistic regression analysis of related risk factors of hypoglycemia of subjects

\begin{tabular}{lllc}
\hline Related factors & $\boldsymbol{p}$ value & OR & $\mathbf{9 5 \% ~ C I}$ \\
\hline $\begin{array}{l}\text { Weight-based daily mean } \\
\text { insulin dose }\end{array}$ & 0.028 & 2.035 & $(1.326$, \\
$(0=\leq 0.50 \mathrm{IU} / \mathrm{kg} /$ day, & & & $2.744)$ \\
$1=>0.50 \mathrm{IU} / \mathrm{kg} /$ day $)$ & & & \\
Combined oral hypoglycemia & 0.015 & 1.793 & $(1.248$, \\
agent $(1=$ acarbose, & & & $2.338)$ \\
$2=$ others $)$ & & & \\
\hline$O R$ & & &
\end{tabular}

OR odds ratio, 95\% CI 95\% confidence interval

22:00 p.m. The receiver-operator characteristic (ROC) curves of nocturnal hypoglycemia predicted by bedtime IG with different insulin regimens and dietary patterns were drawn according to the gold standard of nocturnal hypoglycemia recorded by CGM. The optimal cutoff point is the one with the maximum sum of sensitivity and specificity. The results showed that the area under the ROC curve (AUC) of predicting nocturnal hypoglycemia under an HCD pattern was larger than that under a habitual dietary pattern, and the AUC of the habitual dietary pattern was larger than that of the HFD pattern in the same premixed insulin analog (LM25: $\mathrm{AUC}_{\mathrm{HCD}}$ 0.873, $\mathrm{AUC}_{\text {Habitual }}$
0.810, $\mathrm{AUC}_{\mathrm{HFD}}$ 0.692; LM50: $\mathrm{AUC}_{\mathrm{HCD}}$ 0.863, $\mathrm{AUC}_{\text {Habitual }}$ 0.836, $\mathrm{AUC}_{\mathrm{HFD}} 0.708$, respectively). Under both HCD and habitual diet patterns, the optimal cutoff point values of bedtime glucose predicting nocturnal hypoglycemia in LM50 were lower than those in LM25. Under the habitual dietary pattern, the optimal cutoff point values of bedtime IG in LM25 and LM50 were 6.30 and $5.75 \mathrm{mmol} / \mathrm{l}$, respectively (Table 5, Fig. 2).

\section{DISCUSSION}

At present, the studies on the comparison of low- and mid-ratio premixed insulin analogs mainly focus on their effect on overall and postprandial glucose control. Few studies consider the effect of diet structure on hypoglycemia during insulin treatment. In this study, the data of our previous study, including SMBG and CGM data, were used to analyze the effect of diet patterns on hypoglycemia, related factors of hypoglycemia and predictive value of bedtime glucose on nocturnal hypoglycemia.

Data from SMBG under habitual diet pattern throughout the study showed that the mean number of nocturnal hypoglycemia episodes per patient per year in the LM50 regimen was lower than that in the LM25 regimen. CGM data under three different dietary patterns also

Table 5 Predictive value of bedtime IG on nocturnal hypoglycemia

\begin{tabular}{|c|c|c|c|c|c|c|}
\hline \multirow[t]{2}{*}{ Dietary pattern } & \multicolumn{3}{|l|}{ LM25 } & \multicolumn{3}{|l|}{ LM50 } \\
\hline & $\overline{\mathrm{HCD}}$ & HFD & Habitual & HCD & HFD & Habitual \\
\hline AUC & 0.873 & 0.692 & 0.810 & 0.863 & 0.708 & 0.836 \\
\hline $95 \% \mathrm{CI}$ & $(0.775,0.971)$ & $(0.513,0.872)$ & $\begin{array}{c}(0.694 \\
0.926)\end{array}$ & $\begin{array}{c}(0.766 \\
0.959)\end{array}$ & $\begin{array}{c}(0.495 \\
0.921)\end{array}$ & $\begin{array}{c}(0.725 \\
0.947)\end{array}$ \\
\hline $\begin{array}{l}\text { Optimal cutoff point value } \\
(\mathrm{mmol} / \mathrm{l})\end{array}$ & 5.85 & 5.15 & 6.30 & 5.45 & 5.25 & 5.75 \\
\hline Sensitivity & 0.862 & 0.866 & 0.676 & 0.718 & 0.841 & 0.735 \\
\hline Specificity & 0.813 & 0.500 & 0.846 & 0.900 & 0.667 & 0.769 \\
\hline Youden index & 0.675 & 0.366 & 0.523 & 0.618 & 0.508 & 0.505 \\
\hline
\end{tabular}

$L M 25$ insulin lispro Mix 25, LM50 insulin lispro Mix 50, HCD high-carbohydrate diet, $H F D$ high-fat diet, $A U C$ area under the curve, 95\% CI 95\% confidence interval 

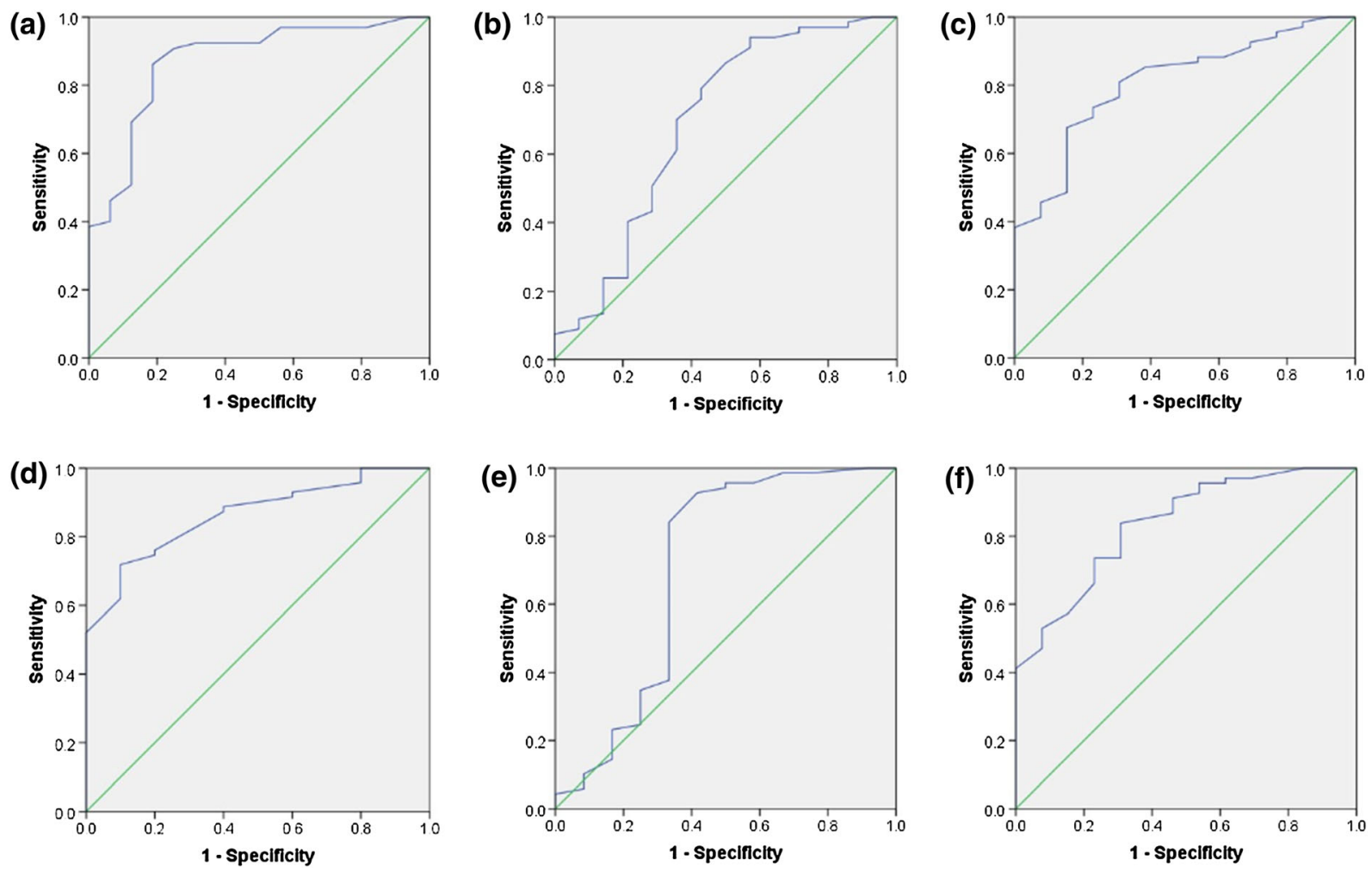

Fig. 2 ROC curves of nocturnal hypoglycemia predicted by bedtime IG with different insulin regimens and dietary patterns. a ROC curve in LM25 and HCD; b ROC curve in LM25 and HFD; c ROC curve in LM25 and habitual diet; $\mathbf{d}$ ROC curve in LM50 and HCD; e ROC curve in
LM50 and HFD; f ROC curve in LM50 and habitual diet. $H C D$ high-carbohydrate diet, HFD high-fat diet, LM25 insulin lispro Mix 25, LMSO insulin lispro Mix 50, ROC receiver-operator characteristic

episodes, especially nocturnal hypoglycemia. Chen et al., in the subgroup analysis of the CLASSIFY study, found no difference in nocturnal hypoglycemia between LM25 and LM50 under the HCD pattern (54\% daily energy intake) [17], which was different from the results of our study. The reason may be that the $\mathrm{HbA}_{1 \mathrm{c}}$ level of the subjects in our study (mean $7.8 \%)$ was lower than that in the CLASSIFY study $(>8.4 \%)$, and the risk of hypoglycemia was higher, so it may be easier to reflect the difference of drug characteristics in hypoglycemia.

The related factors analysis of hypoglycemia in our study showed that the risk of hypoglycemia in patients treated with other oral hypoglycemic agents (metformin and/or thiazolidinediones) was 1.793 times higher than that in patients with acarbose, indicating that which was helpful to reduce hypoglycemia 
premixed insulin analogs combined with acarbose were more helpful in reducing the incidence of hypoglycemia than those combined with other oral hypoglycemic agents, consistent with the results of previous reports [18]. Acarbose combined with premixed insulin analogs twice a day can reduce BG variability and hypoglycemia events. Another related factor was daily mean insulin dose. This study found that hypoglycemia was negatively correlated with weight-based daily mean insulin dose, and the risk of hypoglycemia in patients with daily mean dose $\leq 0.50 \mathrm{IU} / \mathrm{kg} /$ day was 2.35 times that in patients with daily mean dose $>0.50 \mathrm{IU} /$ $\mathrm{kg} /$ day. Patients with a small daily mean insulin dose were more sensitive to insulin and therefore were more prone to hypoglycemia. A retrospective study of hypoglycemia risk factors in hospitalized patients also found that weightbased daily insulin dose of patients with two or more hypoglycemia risk factors was lower than that of patients with one or less hypoglycemic risk factor [19]. It was suggested that more attention should be paid to preventing hypoglycemia in patients with lower weight-based daily mean insulin dose, although it was possible that their total daily insulin dose was lower.

CGM can continuously monitor all-day IG, which may provide more information than the fingertip BG measurement; in particular, it could find many asymptomatic nocturnal hypoglycemia events. Some studies have explored the relationship between bedtime glucose and nocturnal hypoglycemia. Pramming et al.'s study on patients treated with insulin found that $80 \%$ of patients with bedtime $\mathrm{BG}<6 \mathrm{mmol} / \mathrm{l}$ may develop nocturnal hypoglycemia [20]. Shalwitz et al.'s study on children with type 1 diabetes found that bedtime $\mathrm{BG}<5.6 \mathrm{mmol} / \mathrm{l}$ had a positive predictive value of $24 \%$ and a negative predictive value of $90 \%$ for following nocturnal hypoglycemia [21]. Li et al., using CGMS to study T2DM patients treated with insulin pumps, found that bedtime BG $5.9 \mathrm{mmol} / \mathrm{l}$ was the optimal cut point for predicting nocturnal hypoglycemia; its sensitivity was $54.5 \%$ and specificity was $77.8 \%$ [22]. Because the occurrence of nocturnal hypoglycemia was closely related to the type of diabetes, dietary pattern, medication type and so on, the prediction of nocturnal hypoglycemia in a specific population had its own specific cut point. Our study, using CGM data at the end of each stage of treatment, analyzed whether bedtime glucose could predict nocturnal hypoglycemia under different dietary patterns and different insulin regimens. We found that ROC curves of nocturnal hypoglycemia predicted by bedtime IG under HCD and habitual diet had higher predictive values than those under HFD, regardless of the treatment assigned. This may be because nocturnal hypoglycemia was more likely to occur in HCD than in HFD. In the habitual dietary pattern, the optimal cutoff point values of bedtime glucose predicting nocturnal hypoglycemia were 6.30 and $5.75 \mathrm{mmol} / \mathrm{l}$ for LM25 and LM50, respectively. In the Chinese habitual diet, the safety range of bedtime glucose for the LM50 regimen was wider than that of the LM25 regimen.

The advantage of this study was to compare all aspects of hypoglycemia between LM25 and LM50 in detail, especially to explore the effect of dietary patterns on hypoglycemia, which provided a reference for clinicians to make clinical decisions. The first limitation of this study was that the study population was relatively small and may not have been powered enough to address some questions. Second, this study was only a post hoc analysis, and the conclusions have not been tested in an independent population. Finally, the observations made could be limited by the ethnicity of the study population, and findings may be different in different ethnic groups.

\section{CONCLUSION}

This study showed that the risk of nocturnal hypoglycemia in the LM50 regimen was lower than that in the LM25 regimen under the HCD pattern and the safety range of bedtime glucose for the LM50 regimen was wider than that of the LM25 regimen in Chinese T2DM patients. Premixed insulin analogs combined with acarbose were more helpful to reduce the incidence of hypoglycemia. 


\section{ACKNOWLEDGEMENTS}

We thank the participants of the study.

Funding. This study was funded by Lilly Suzhou Pharmaceutical Co., Ltd. (Shanghai Branch, China), and the Non-profit Central Research Institute Fund of Chinese Academy of Medical Sciences (no. 2017PT32020, no. 2018PT32001). The journal's Rapid Service fee was funded by the authors. All authors had full access to all of the data in this study and take complete responsibility for the integrity of the data and accuracy of the data analysis.

Authorship. All named authors meet the International Committee of Medical Journal Editors (ICMJE) criteria for authorship for this manuscript, take responsibility for the integrity of the work as a whole, and have given final approval to the version to be published. Prof. $\mathrm{Y}$. $\mathrm{Li}$ is the guarantor for the study and takes full responsibility for the integrity of the work as a whole, from inception to published article.

Disclosures. Wei Li, Fan Ping, Lingling Xu, Huabing Zhang, Yaxiu Dong, Kang Yu, and Yuxiu Li have nothing to disclose.

Compliance with Ethics Guidelines. This study was approved by the PUMCH Ethics Committee and followed the ethical standards of the responsible committee on human experimentation (institutional and national) and with the Helsinki Declaration of 1964, as revised in 2013. All patients signed informed consent before enrollment.

Data Availability. The datasets generated and/or analyzed during the current study are available from the corresponding author on reasonable request.

Open Access. This article is distributed under the terms of the Creative Commons Attribution-NonCommercial 4.0 International License (http://creativecommons.org/licenses/ by-nc/4.0/), which permits any noncommercial use, distribution, and reproduction in any medium, provided you give appropriate credit to the original author(s) and the source, provide a link to the Creative Commons license, and indicate if changes were made.

\section{REFERENCES}

1. Chan JC, et al. Diabetes in the Western Pacific Region-past, present and future. Diabetes Res Clin Pract. 2014;103(2):244-55.

2. Wang L, et al. Prevalence and ethnic pattern of diabetes and prediabetes in China in 2013. JAMA. 2017;317(24):2515-23.

3. Davies MJ, et al. Management of hyperglycemia in type 2 diabetes, 2018. A Consensus Report by the American Diabetes Association (ADA) and the European Association for the Study of Diabetes (EASD). Diabetes Care. 2018;41(12):2669-701.

4. Chinese Diabetes Society. Chinese guideline for the prevention and treatment of type 2 diabetes mellitus (2017 edition). Chin J Diabetes Mellitus 2018;10(1):4-67.

5. Ji LN, et al. Glycemic control among patients in China with type 2 diabetes mellitus receiving oral drugs or injectables. BMC Public Health. 2013;13: 602.

6. Qian L, et al. Early insulin secretion failure leads to diabetes in Chinese subjects with impaired glucose regulation. Diabetes Metab Res Rev. 2009;25(2): 144-9.

7. Mitsui R, et al. Factors responsible for deteriorating glucose tolerance in newly diagnosed type 2 diabetes in Japanese men. Metabolism. 2006;55(1): 53-8.

8. Li R, et al. Increasing prevalence of type 2 diabetes in Chinese adults in Shanghai. Diabetes Care. 2012;35(5):1028-30.

9. Watada $\mathrm{H}$, et al. Comparison of insulin lispro mix 25 with insulin lispro mix 50 as an insulin starter in Asian patients with type 2 diabetes: a phase 4 , openlabel, randomized trial (CLASSIFY study). Diabetes Metab Res Rev. 2017;33(1):e2816.

10. Li W, et al. Effects of insulin lispro mix 25 and insulin lispro mix 50 on postprandial glucose excursion in patients with type 2 diabetes: a prospective, open-label, randomized clinical trial. Diabetes Ther. 2018;9(2):699-711.

11. Garg R, et al. Hypoglycemia, with or without insulin therapy, is associated with increased mortality 
among hospitalized patients. Diabetes Care. 2013;36(5):1107-10.

12. Turchin A, et al. Hypoglycemia and clinical outcomes in patients with diabetes hospitalized in the general ward. Diabetes Care. 2009;32(7):1153-7.

13. Boucai L, Southern WN, Zonszein J. Hypoglycemiaassociated mortality is not drug-associated but linked to comorbidities. Am J Med. 2011;124(11): 1028-35.

14. Alrwisan A, Ross J, Williams D. Medication incidents reported to an online incident reporting system. Eur J Clin Pharmacol. 2011;67(5):527-32.

15. Cobaugh DJ, et al. Enhancing insulin-use safety in hospitals: practical recommendations from an ASHP Foundation expert consensus panel. Am J Health Syst Pharm. 2013;70(16):1404-13.

16. Su $\mathrm{Q}$, et al. Comparison of insulin lispro mix 25 with insulin lispro mix 50 as insulin starter in Chinese patients with type 2 diabetes mellitus (CLASSIFY study): subgroup analysis of a phase 4 open-label randomized trial. J Diabetes. 2017;9(6): 575-85.

17. Chen $W$, et al. Impact of diet on the efficacy of insulin lispro mix 25 and insulin lispro mix 50 as starter insulin in East Asian patients with type 2 diabetes: Subgroup analysis of the Comparison Between Low Mixed Insulin and Mid Mixed Insulin as Starter Insulin For Patients with Type 2 Diabetes Mellitus (CLASSIFY Study) randomized trial. J Diabetes Investig. 2017;8(1):75-83.

18. Su JB, et al. Glycemic variability in insulin treated type 2 diabetes with well-controlled hemoglobin A1c and its response to further treatment with acarbose. Chin Med J (Engl). 2011;124(1):144-7.

19. Mathioudakis N, Everett E, Golden SH. Prevention and management of insulin-associated hypoglycemia in hospitalized patients. Endocr Pract. 2016;22(8):959-69.

20. Pramming S, et al. Nocturnal hypoglycaemia in patients receiving conventional treatment with insulin. Br Med J (Clin Res Ed). 1985;291(6492): 376-9.

21. Shalwitz RA, et al. Prevalence and consequences of nocturnal hypoglycemia among conventionally treated children with diabetes mellitus. J Pediatr. 1990;116(5):685-9.

22. Li M, et al. Prediction of nocturnal hypoglycaemia with bedtime glucose level during continuous subcutaneous insulin infusion in type 2 diabetics. Zhonghua Yi Xue Za Zhi. 2010;90(42):2962-6. 